\title{
Repensando o ensino de Anatomia Humana para Educação Física baseado nas tendências educacionais do século XXI
}

\author{
Rethinking the teaching of Human Anatomy for Physical Education based on educational trends of
}

the 21st century

Repensar la enseñanza de la Anatomía Humana para la Educación Física a partir de las tendencias educativas del siglo XXI

\section{Resumo}

O ensino de Anatomia Humana ainda se utiliza do modelo tradicional, conteudista, voltado para memorização tornando-o desinteressante na perspectiva dos alunos. Este trabalho tem por objetivo apresentar inovações pedagógicas, construídas a partir do uso de metodologias ativas de aprendizagem e ferramentas digitais para licenciandos em Educação Física. Foi desenvolvida uma pesquisa para averiguar as tendências educacionais para o século XXI. Foram incorporadas as seguintes tendências: ensino híbrido, sala de aula invertida e gamificação. Para tal, foi criado um Ambiente Multimodal de Ensino Híbrido contendo três ambientes on-line (plataforma Moodle, Facebook e Instagram) e dois ambientes off-line (sala de aula teórica e laboratório de aula prática). Além do que, os conteúdos anatômicos foram abordados de forma sistêmica, multimodal, interdisciplinar, com foco no professor de Educação Física e na sua prática profissional. Espera-se que a proposta apresentada possa contribuir para o ensinoaprendizagem de Anatomia para os graduandos de Educação Física.

Palavras-chave: Ensino; Ensino de anatomia; Educação física; Ensino híbrido; Sala de aula invertida; Gamificação.

\begin{abstract}
The teaching of Human Anatomy still uses the traditional model, contentist, focused on memorization, making it uninteresting from the students' perspective. This work aims to present pedagogical innovations, built from the use of active learning methodologies and digital tools for Physical Education graduates. Research was carried out to ascertain educational trends for the 21 st century. The following trends were incorporated: hybrid teaching, inverted classroom and gamification. For this, a Multimodal Hybrid Teaching Environment was created containing three online environments (Moodle platform, Facebook and Instagram) and two offline environments (theoretical classroom and practical laboratory). In addition, anatomical contents were approached in a systemic, multimodal, interdisciplinary manner and with a focus on professional practice. It is hoped that the proposal presented can contribute to the teaching and learning of Anatomy for undergraduate Physical Education students.

Keywords: Teaching; Teaching anatomy; Physical education; Hybrid teaching; Inverted classroom; Gamification.

\section{Resumen}

La enseñanza de Anatomía Humana todavía utiliza el modelo tradicional, orientado al contenido, centrado en la memorización, lo que lo hace poco interesante desde la perspectiva de los estudiantes. Este trabajo tiene como objetivo presentar innovaciones pedagógicas, construidas a partir del uso de metodologías de aprendizaje activo y herramientas digitales para estudiantes de Educación Física. Se llevó a cabo una encuesta para conocer las tendencias educativas para el siglo XXI. Se incorporaron las siguientes tendencias: enseñanza híbrida, aula invertida y gamificación. Para ello, se creó un Entorno Docente Híbrido Multimodal, que contiene tres entornos online (plataforma Moodle, Facebook e Instagram) y dos entornos offline (aula teórica y aula práctica de laboratorio). Además, los contenidos anatómicos se abordaron de manera sistémica, multimodal, interdisciplinaria, con un enfoque en el docente de Educación Física y su práctica profesional. Se espera que la propuesta presentada pueda contribuir a la enseñanza-aprendizaje de Anatomía para los estudiantes de pregrado de Educación Física.
\end{abstract}


Palabras clave: Enseñanza; Enseñanza de la anatomía; Educación física; Enseñanza híbrida; Aula invertida; Gamificación.

\section{Introdução}

O ensino de Anatomia humana, ainda se utiliza do modelo tradicional de aprendizagem, no qual se prioriza a transmissão de conteúdos, focada na memorização das estruturas anatômicas (Schultz, 2017; RAMOS et al., 2020). Mesmo sabendo que esta realidade vem mudando, um dos problemas que persistem no ensino-aprendizagem de Anatomia para Educação Física, é a forma inadequada como são conduzidas as aulas. Com longas exposições teóricas seguidas de aulas práticas no cadáver, o ensino é direcionado para identificação das estruturas anatômicas, com excessos de termos técnicos que, comumente, necessitam ser apreendidos em curto espaço de tempo (Crochemore \& Marques, 2017). Isso gera um círculo vicioso, no qual o aluno memoriza as estruturas sem tempo para assimilar os conceitos e saber como aplicá-los. Felizmente este panorama começou a se alterar. $\mathrm{O}$ estudo da anatomia vem assumindo uma abordagem prática, aplicada ao movimento e ao funcionamento de um corpo saudável (Crochemore \& Marques, 2017; Piazza \& Chassot, 2011).

Para os licenciados em Educação Física, Anatomia costuma ser pré-requisito para as disciplinas como Fisiologia (geral e aplicada), Cinesiologia, Biomecânica e Musculação, sendo necessário reunir uma base sólida de aprendizagem para alicerçar as disciplinas supracitadas (EEFD, 2006). O projeto pedagógico do curso busca a formação de habilidades e competências como a compreensão morfofuncional dos sistemas orgânicos, com ênfase no sistema locomotor e sua aplicação nos diversos contextos do professor de Educação Física. O estudante de Educação Física deve ser estimulado na busca e produção de novos conhecimentos advindos de pesquisas científicas e práticas de extensão, visando seu aperfeiçoamento permanente. Estas habilidades são ferramentas que prepararam os futuros professores para uma atuação reflexiva, crítica, transformadora e democrática (EEFD, 2006).

Dessa forma, o docente que ministra a disciplina de Anatomia para Educação Física, precisa entender que o objetivo principal não é o de formar anatomistas e nem especialistas diretamente ligados à área da saúde, entretanto ajudar aos licenciandos, futuros professores, na aplicação do conhecimento anatômico em sua prática profissional. Segundo Montes e Souza (2010), são dois os desafios do professor de anatomia: (1) escolher quais são as estruturas anatômicas mais importantes para serem aprendidas pelos alunos, que contribuirão para sua formação profissional e (2) a necessidade de se romper com os modelos tradicionais, por meio das metodologias ativas de aprendizagem. Fontes et al. (2021), concluem que essas metodologias rompem com o modelo tradicional de ensino e que essa ruptura deve ser feita gradualmente, pois as instituições de ensino superior (IES) ainda não estão preparadas para implementação desses recursos na prática pedagógica e docente. De acordo com Moran (2015, p. 18), “as metodologias ativas são pontos de partida para avançar para processos mais avançados de reflexão, de integração cognitiva, de generalização, de reelaboração de novas práticas”.

Assim sendo, este artigo tem por objetivo descrever inovações pedagógicas, que foram construídas a partir do uso de metodologias ativas de aprendizagem e ferramentas digitais, contextualizando o ensino de Anatomia Humana com conteúdos relevantes para professor de Educação Física.

A Anatomia Humana é uma ciência descritiva que possui termos próprios para as diversas estruturas e processos do corpo (Moore et al., 2014). Atualmente o seu aprendizado está baseado em uma abordagem funcional e, nesse contexto de estrutura/função, “a anatomia é o cenário (estrutura) no qual ocorrem os eventos (funções) da vida” (Moore et al., 2014, p. 2). Para o entendimento do corpo na sua totalidade, a Anatomia precisa estar integrada as outras disciplinas (Williams et al., 1995). A abordagem deve ser interdisciplinar e o estudo do conteúdo anatômico deve ir além da memorização das estruturas, desenvolvendo competências para favorecer o aprendizado significativo e permanente, tendo o professor como um mediador do processo de ensino-aprendizagem (Ramos et al., 2020). Destaca-se cada vez mais a importância de se pensar em disciplinas 
com propostas que privilegiem a aprendizagem ativa dos discentes.

A edição EDUCAUSE do relatório Horizon para educação superior (Alexander et al., 2019) destaca a crescente adoção de inovações no ensino, dentre as quais se destacam as metodologias ativas. Este relatório anual é produzido por uma comunidade internacional dedicada as pesquisas sobre o uso de novas mídias e novas tecnologias. Em 2019, o relatório apontou as seguintes tendências para os próximos anos: os modelos de ensino híbrido, o uso de plataformas de aprendizagem, o uso das redes sociais como espaço informal de aprendizagem, a sala de aula invertida a e gamificação das atividades pedagógicas. Além disso, apontou também a exploração das possibilidades oferecidas pelas ferramentas das Tecnologias Digitais de Informação e Comunicação (TDIC) como os feedbacks mais imediatos e a aprendizagem colaborativa voltada para coautoria de conteúdos. O ensino transpõem tempo e espaço da sala de aula e do saber, as redes móveis, ao mesmo tempo em que facilitam o ensino, lançam ao professor a preocupação de que o aluno deve ter habilidades e competências para viver imerso nessa cultura digital (Boucherville, 2019).

De fato, as TDIC vêm causando grande impacto na forma como as pessoas se relacionam, aprendem e compartilham conhecimento. O conhecimento sai da esfera das instituições de ensino e passa para as mãos da sociedade. Com a informação na palma da mão, o saber é democratizado. Ampliam-se os espaços educativos, o que obriga os educadores a reinventarem a sala de aula para atender às demandas dos jovens que passam progressivamente mais tempo conectados on-line (Tori, 2015).

Para atender essa demanda, surgem metodologias ativas que abrangem várias estratégias de aprendizagem, todas voltadas para a autonomia do estudante, como por exemplo: o ensino híbrido, a sala de aula invertida, os ambientes virtuais de aprendizagem (formal e não formal) e a gamificação. De acordo com Moran (2015), a sala de aula vem se tornando um espaço cada vez mais híbrido, em que as metodologias ativas de aprendizagem, junto com as tecnologias digitais, já fazem parte da realidade escolar. $\mathrm{O}$ aluno se envolve com as atividades propostas e passa a participar do processo de construção do seu próprio conhecimento. Fonseca e Duso (2018), se contrapõem a uma visão reducionista da aprendizagem, pautada pela transferência de conhecimento, sem considerar o que o aluno já conhece. A educação bancária em que o professor transmite os conteúdos e os alunos os recebem de forma passiva (Freire, 1987) não tem mais sentido na educação contemporânea.

Sabendo que os métodos tradicionais não atendem mais de forma plena o estudante globalizado, os professores devem repensar e transformar as aulas preparadas em formato expositivo, em aulas dialogadas, provocativas, com formato mais inovador, que contemple pausas, desafios, discussões em grupo e exposições precisas do docente (Pereira; Lima, 2018).

Diante do exposto acima, a solução encontrada foi propor inovações pedagógicas, construídas a partir do uso de metodologias ativas de aprendizagem, partindo do ensino híbrido, com o uso da modalidade da sala de aula invertida, da gamificação com o uso de elementos do jogo, da plataforma Moodle como um espaço formal de ensino e das redes sociais como um espaço não formal de ensino. Dessa forma, as metodologias ativas de aprendizagem assim como as ferramentas digitais abordadas neste trabalho serão delineadas em seguida.

\section{Ensino híbrido}

O modelo híbrido de ensino, semipresencial ou blended learning, é uma combinação metodológica entre o ensino presencial e o ensino on-line. Nesta modalidade o processo de ensino aprendizagem ocorre em dois momentos distintos que se complementam. Um momento off-line, em sala de aula presencial, com os alunos interagindo face a face e um momento online, com o uso de tecnologias digitais dando mais autonomia ao aluno (Bacich, 2020).

A educação nunca teve uma fórmula única, muito pelo contrário, sempre foi uma mistura, um blended de diversas combinações como espaços, atividades, metodologias entre outros, sendo que agora, todo esse processo de ensinoaprendizagem aliado a mobilidade e conectividade permitiu a criação de um ecossistema mais aberto e criativo (Bacich \& Moran, 2015). Posto isso, as TDIC diversificaram e multiplicaram as formas de aprender e ensinar. Em relação às inovações 
pedagógicas no ensino superior, Moran et al. (2013) destacam que o professor deve parar de transmitir todo o conteúdo da matéria e passar a propor novos desafios aos alunos, estimulando a busca do próprio conhecimento por meio da pesquisa. Os autores vão além, sugerindo o uso da sala de aula invertida para uma integração do presencial com o digital, integrando os ambientes on-line e off-line. E afirmam que a melhor forma de aprender é combinando desafios com informações contextualizadas. A aprendizagem efetiva ocorre quando o conteúdo a ser assimilado tem relação direta com a sua prática na vida real.

\section{Sala de aula invertida}

A sala de aula invertida ou flipped classroom é uma metodologia ativa de aprendizagem, colocada em prática pelos educadores norte-americanos Jonathan Bergmam e Aaron Sams, que aplicaram um modelo de aula fora dos padrões tradicionais. Segundo Bergmann e Sams (2012), o processo de ensino tradicional, no qual o professor expõe o conteúdo, os alunos tomam notas e depois completam as tarefas em casa deve ser literalmente invertido. Ao invés dos alunos fazerem anotações em sala de aula, enquanto o professor discorre sobre um determinado tema, eles revisam na aula, a matéria estudada previamente em casa.

A sala de aula invertida é uma contraposição à sala de aula tradicional, sendo baseada na discussão sobre os papéis de alunos e professores. Portanto quando se adota a modalidade híbrida da sala de aula invertida, se rejeita o modelo tradicional em que o professor apresenta os conteúdos para os alunos absorverem e reproduzirem.

Na modalidade invertida, os alunos passam a estudar o conteúdo antes da aula por meio de atividades on-line disponibilizadas num ambiente virtual de aprendizagem (AVA), de forma que se preparem para as atividades que serão propostas na sala de aula presencial. Desta forma, sobra mais tempo para desenvolver outras atividades em sala de aula como: trabalhos em equipe, jogos, apresentações, tirar dúvidas da matéria etc.

\section{Gamificação}

A gamificação do aprendizado é uma das tendências para o século 21 apontadas pela edição de 2019 do NMC Horizon Report Higher Education (Alexander et al., 2019). O termo gamificação, do inglês gamification, significa "o uso de elementos de design de games em contextos que não são de games" (Deterding et al., 2011). Gamificar o ensino é aplicar os recursos dos jogos como: pontuação, regras, recompensas entre outros para engajar os alunos de forma lúdica e divertida nas atividades propostas em ambientes de aprendizagem. Nesse sentido, a gamificação é um recurso facilitador da aprendizagem.

"A gamificação é uma abordagem emergente de instrução que facilita o aprendizado e incentiva a motivação por meio do uso de elementos de jogo, mecânica e pensamento baseado em jogo. Na gamificação, o aluno não joga um jogo inteiro do início ao fim; em vez disso, eles participam de atividades que incluem elementos de jogos, como ganhar pontos, superar um desafio ou receber distintivos por realizar tarefas (Kapp, 2013, Kapp Notes, tradução própia)."

Pereira et al. (2019) se mostram cautelosos quanto à gamificação na aprendizagem, afirmando que ainda é necessária uma investigação mais profunda em relação ao tema, mas alega que o ensino gamificado pode melhorar o aprendizado profundo pelo fato de aumentar o interesse do aluno.

\section{Plataforma Moodle}

O Moodle (Modular Object-Oriented Dynamic Learning Environment) é um sistema de gerenciamento da aprendizagem (SGA) lançado em 2001 pelo australiano Martin Dougiamas. O Moodle é um software livre muito utilizado para criar ambientes virtuais de aprendizagem por oferecer diversas funcionalidades, permitindo planejamento, implementação e avaliação. É uma das plataformas de EAD (educação a distância) mais utilizadas no mundo, com usuários registrados em mais 
de 245 países (MoodleNet, 2021).

Segundo seu criador, o Moodle foi projetado para facilitar a elaboração de ambientes de aprendizagem pelos educadores. A ideia é de peças que vão se encaixando e construindo um ambiente customizado. A plataforma permite disponibilizar uma variedade de conteúdos para engajar o aluno na busca do conhecimento. Os feedbacks constantes e imediatos ajudam a consolidar o aprendizado.

Silva (2020), ao recomendar um meio digital para que o professor disponibilize os conteúdos da disciplina, sugere a utilização de um ambiente virtual de aprendizagem como o Moodle, pois permite de forma simples, o compartilhamento de textos, videoaulas, envio de relatórios, resenhas ou resumos e a utilização de questionários e enquetes.

\section{Redes sociais}

O relatório "Digital in 2020", realizado pelo We Are Social e Hootsuite, descreve a população do Brasil como altamente conectada, ocupando o segundo lugar em termos de horas gastas em plataformas de redes sociais por dia, 3 horas e 34 minutos, sendo 130 milhões de brasileiros no Facebook e 69 milhões no Instagram (WE ARE SOCIAL, 2020). No que diz respeito ao ensino-aprendizagem, as mídias sociais são ferramentas importantes de apoio ao letramento informacional, além de serem conteúdos de aprendizagem necessários aos aprendizes (Gasque, 2016). Em relação ao uso da rede social Facebook como ambiente virtual de aprendizagem, Bernardo et al. ressaltam que:

\footnotetext{
"A utilização da rede social Facebook como ambiente virtual de aprendizagem tem um grande potencial pedagógico. Essa rede social pode ser bem utilizada como um espaço virtual de aprendizagem formal, estimulando os educandos no processo de aquisição do saber. O Facebook tornou-se uma ferramenta inovadora para desenvolver práticas pedagógicas atraentes, que chamam a atenção dos alunos, visto que já conhecem esse universo, tornando essa experiência uma troca de saberes e consequentemente aprendizagem mútua (Bernardo et al., 2020, p. 844).”
}

Nesse contexto, as redes sociais on-line, como o Facebook e o Instagram, podem vir a ser um espaço distinto para o ensino-aprendizagem, por ter grande repercussão, especialmente entre jovens.

\section{Metodologia}

O ponto de partida para o presente artigo foi realizar uma pesquisa bibliográfica para averiguar as tendências educacionais para o século XXI. Após a pesquisa, foi escolhido um modelo híbrido de ensino, promovendo uma combinação entre o ensino presencial e on-line, aprendizagem móvel e aprendizagem por meio das redes sociais. No meio dessa alteração de contexto presencial para semipresencial, adotou-se uma abordagem pedagógica centrada na autonomia do estudante, com o intuito de desenvolver as competências necessárias para estimular a aprendizagem.

A metodologia desse estudo foi construída a partir do "CICLO PDCA", uma abreviatura em inglês para as palavras Plan-Do-Check-Act. Em português significa Planejar, Executar, Checar e Agir. O ciclo foi concebido em 1920 pelo físico Walter Shewhart, e aperfeiçoado por Deming que promoveu o PDCA como uma ferramenta para atingir a melhoria contínua de qualquer processo. O modelo é usado até hoje para planejar uma ação, executar o que foi planejado, verificar o que deu certo e fazer os ajustes necessários (Deming, 1990). Em seu artigo "Pesquisa-ação: uma introdução metodológica", David Tripp (2005) cita o ciclo PDCA, e discorre sobre as quatro etapas contínuas, sistemáticas e fundamentadas empiricamente de melhoraria de determinada prática. Essas etapas são inerentes ao trabalho do professor, sendo uma prática sistêmica de todo processo pedagógico. Segue abaixo o infográfico do ciclo PDCA empregado para melhoria da qualidade no processo de ensino-aprendizagem de Anatomia (Figura 1). 
Figura 1 - Infográfico sobre o Ciclo PDCA.

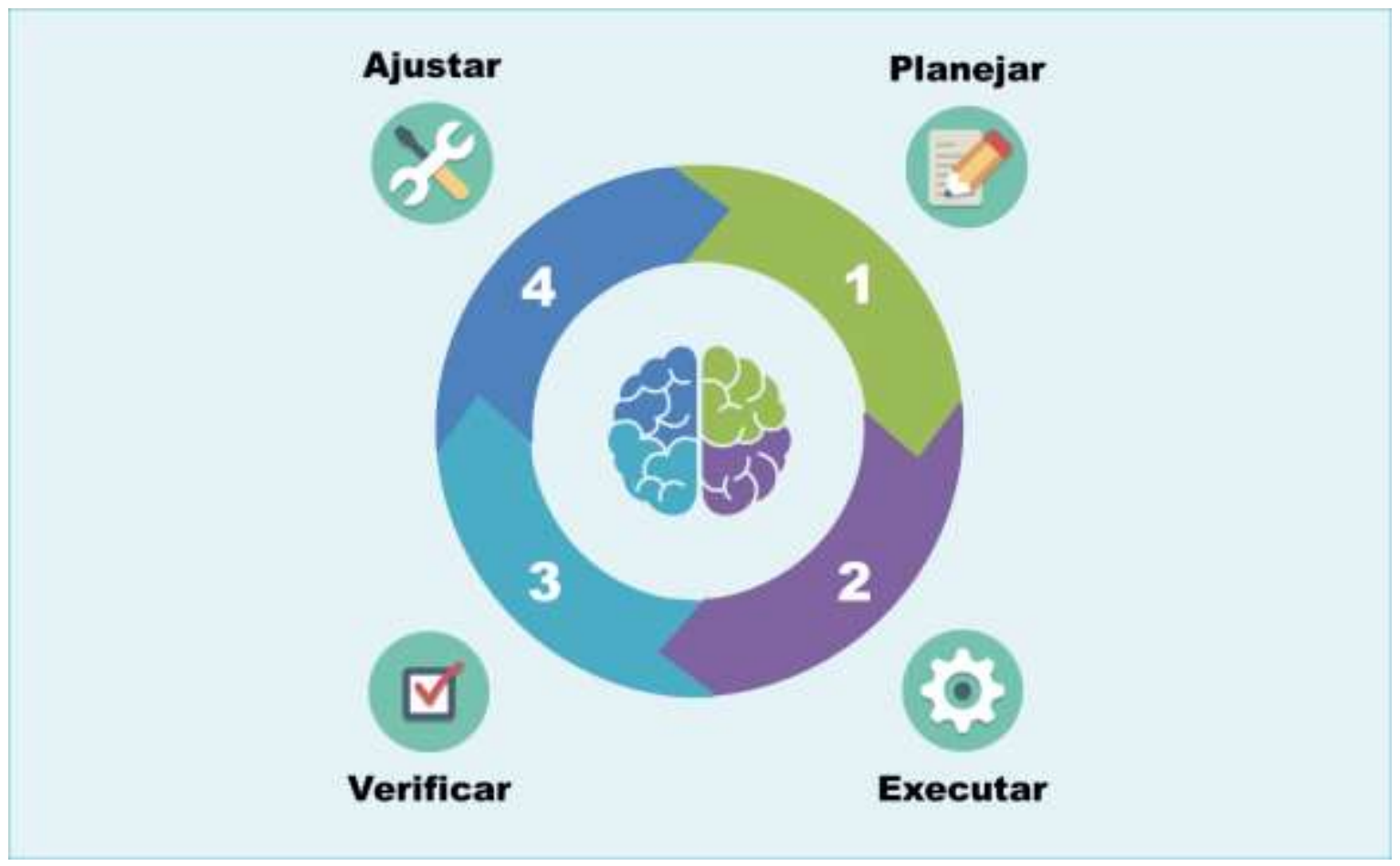

Fonte: Autores.

O planejamento do modelo híbrido de ensino de Anatomia para Educação Física, descrito neste trabalho, vem sendo desenvolvido e aprimorado desde 2015, sempre incluindo e mantendo conteúdos relevantes para o licenciando e excluindo os que não estão dentro do contexto da profissão. As atividades foram criadas usando as metodologias ativas de ensino, com o objetivo de tornar os alunos mais autônomos e manter o interesse deles nas aulas.

As inovações pedagógicas planejadas cuidadosamente antes do início de cada semestre foram executadas durante o período letivo. Verificou-se a eficiência de cada atividade. A verificação, das atividades on-line, se deu na plataforma Moodle pela navegação no ambiente e notas obtidas (quadro de notas), enquanto que nas redes sociais da disciplina, pelas curtidas e comentários. Nas aulas teóricas, observou-se a participação do aluno tirando dúvidas, discutindo sobre o conteúdo que estava sendo abordado e respondendo as questões propostas nos slides. Durante as aulas práticas no laboratório de anatomia, os desafios em equipe foram verificados pelo interesse em resolvê-los, pela participação de todos da equipe e se executaram com êxito. Após o final de cada aula, a atividade era: (1) aprovada para o próximo período, (2) ajustada para ser aplicada novamente em outra ocasião ou (3) rejeitada. O ciclo foi mantido por oito semestres seguidos, sempre procurando renovar e inovar até chegar ao modelo híbrido descrito neste trabalho.

\section{Resultados e Discussão}

A estrutura da disciplina de Anatomia para Educação Física foi adaptada de presencial para o semipresencial, baseada nas tendências educacionais para o século XXI, descritas no relatório Horizon para educação superior (Alexander et al., 2019). São elas: as modalidades de ensino híbrido, a sala de aula invertida, o uso das redes sociais como espaço informal de aprendizagem e a gamificação das atividades pedagógicas. Essas inovações pedagógicas, no ensino aprendizagem de anatomia, tiveram como objetivo tornar a disciplina relevante, abordar conteúdos anatômicos com foco na prática profissional, oferecer feedback imediato para manter os alunos engajados numa aprendizagem mais ativa, colocando o aluno no centro do processo. 
A adoção dessas inovações na disciplina de Anatomia exigiu uma reorganização e adequação a uma nova proposta de ensinoaprendizagem, começando pela modalidade híbrida escolhida, que foi a sala de aula invertida.

A disciplina semipresencial foi planejada em cinco ambientes de aprendizagem. Três ambientes on-line e dois ambientes off-line. Os cinco ambientes se integram formando o Ambiente Multimodal de Ensino Híbrido (AMEH). Os três ambientes on-line de aprendizagem são a Plataforma Moodle, o Facebook e o Instagram. Os dois ambientes off-line de aprendizagem são a sala de aula teórica e o laboratório de aula prática (Anatômico) (Figura 2).

Figura 2 - Infográfico sobre a estrutura do Ambiente Multimodal de Ensino Híbrido (AMEH).

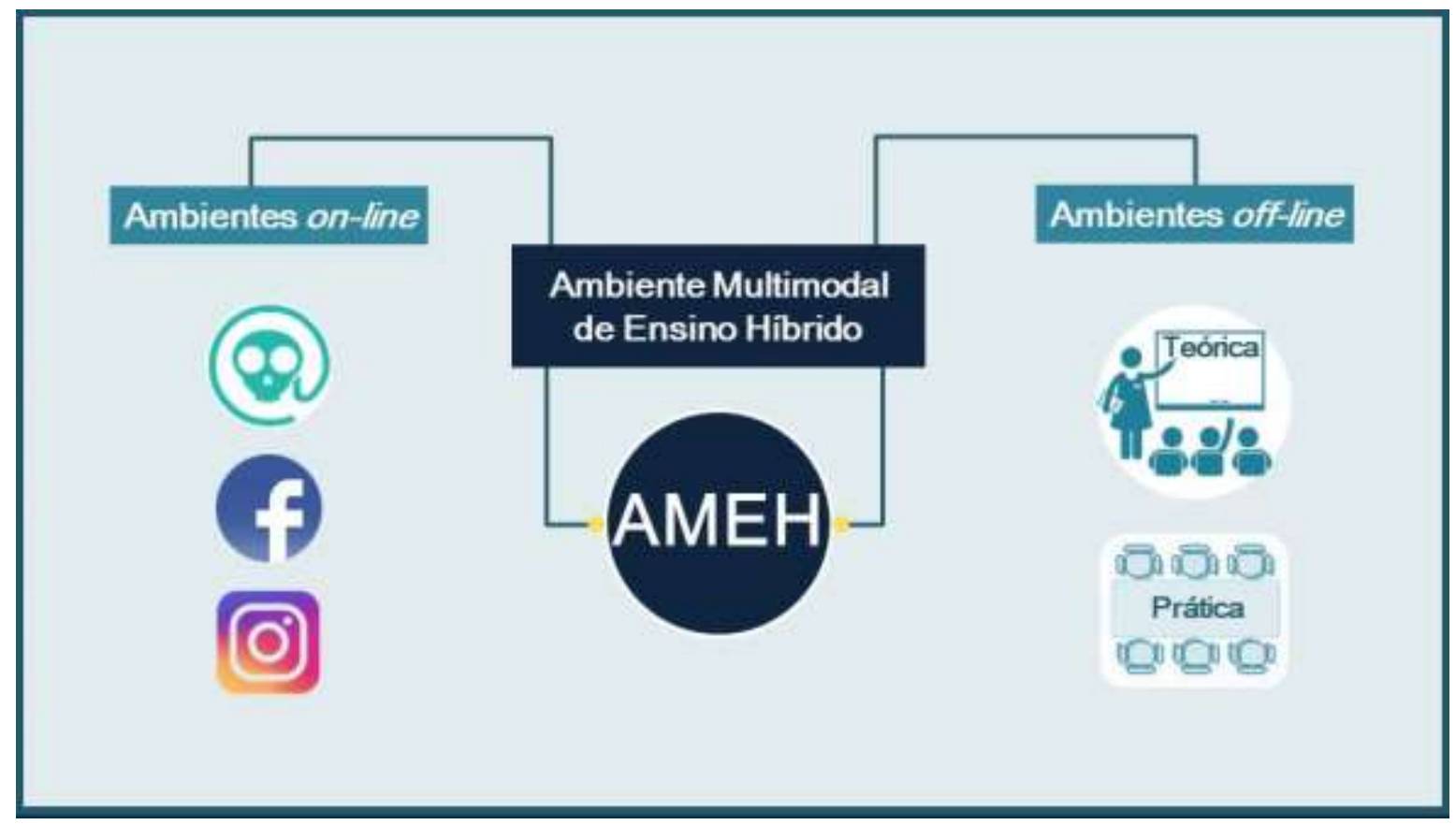

Fonte: Autores.

O Ambiente Multimodal de Ensino Híbrido (AMEH) foi planejado para que o conteúdo fosse ofertado em vários ambientes de aprendizagem de maneira formal e não formal, de forma individual ou em grupo e com a utilização de diversos recursos como: textos, imagens, vídeos, áudios, jogos, memes, paródias de músicas etc. No ensino multimodal "o aluno aprende através de ferramentas visuais, auditivas, leituras, escritas e atividades cinestésicas" (Massari et al., 2020). O benefício do aprendizado encontra-se na interconexão entre: as atividades disponibilizadas no Moodle, as metodologias aplicadas nos laboratórios didáticos e nas ferramentas encontradas na internet (Lacerda \& Silva, 2016).

Segundo Moran et al., (2013), quando se consegue integrar todas as tecnologias de forma inovadora, parte importante do aprendizado acontece. Nesse contexto, no planejamento do AMEH levou-se em conta que cada indivíduo tem um modo próprio de aprender e o uso de múltiplas modalidades permite uma estratégia de ensino diversificada atendendo aos vários tipos de aprendizes.

Por ser um ambiente formal de aprendizagem, a maior parte das atividades on-line da disciplina foi disponibilizada para os alunos no Moodle. O AVA "é uma opção para avançar na incorporação de metodologias e estratégias inovadoras que ampliem, reforcem e motivem a aprendizagem dos alunos ao longo do tempo" (ORNASS et al., 2020). Para ampliar o AVA, o ambiente formal de aprendizagem (Moodle) foi integrado a dois ambientes não formais de aprendizagem, o Facebook e Instagram, que segundo Yamaguchi et al. (2020) são ambientes alternativos para a educação não formal.

$\mathrm{O}$ uso da sala invertida mudou o foco da aprendizagem, o ensino passou a ser centrado no aluno. $\mathrm{O}$ aluno foi estimulado a estudar, pesquisar, pensar, resolver questões, interagir com os colegas nos ambientes on-line, tudo isso antes da 
aula presencial sobre determinado conteúdo. O aluno chegava à sala de aula presencial com uma base da matéria, sobrando mais tempo para desenvolver as atividades em grupo e de aplicação do conhecimento adquirido (Bacich \& Moran, 2018). No próximo tópico, será descrita a construção do Curso de Treinamento em Anatomia - CURT@, o principal ambiente digital da disciplina.

\section{Curso de Treinamento em Anatomia - Curt@}

O principal ambiente on-line, CURT@ - acrônimo para Curso de Treinamento em Anatomia, foi criado na plataforma Moodle do ambiente virtual de aprendizagem de uma Instituição Federal de Ensino Superior (IFES).

Com a finalidade de criar uma identidade ao principal ambiente on-line da disciplina e inserir o aluno no processo de gamificação o nome escolhido foi Curso de Treinamento em Anatomia-CURT@. O aluno foi inserido no processo de ensinoaprendizagem como um atleta, que precisava cumprir seus treinos semanais para ter um bom desempenho nas avaliações. O posicionamento para criação do nome foi embasado no fato que o termo treinamento para o professor de Educação Física significar todo um processo sistemático, progressivo, individualizado, de aperfeiçoamento em busca de um objetivo:

"O treinamento físico é uma importante área de atuação profissional da Educação Física e do Esporte. Ela tem por objetivo precípuo, a melhoria do desempenho físico-esportivo através da aplicação de um processo organizado e sistemático composto por exercícios físicos (Roschel et al., 2011, p. 53).”

A opção pelo nome "Curso de Treinamento em Anatomia - CURT@" teve o intuito de transmitir em poucas palavras a contextualização da disciplina para o aluno de Educação Física. O nome traz dessa forma, toda uma interpretação do termo treinamento, passando a ideia de um processo organizado, individualizado, progressivo, sistemático, de aperfeiçoamento em busca do aprendizado de anatomia. O treinamento ocorreu com a utilização de metodologias ativas de aprendizagem e por meio de diversas atividades on-line que interagiram com as atividades presenciais. $\mathrm{O}$ acrônimo Curt@ remete a ideia do ato de curtir que é uma característica das redes sociais e vai ao encontro da utilização do Facebook e Instagram como expansão do ambiente digital de aprendizagem da disciplina. Definido o nome veio à construção da assinatura visual.

A assinatura visual foi composta por um logotipo e um símbolo (Figura 3). Entende-se por logotipo o desenho da escrita de um nome, e como símbolo a representação gráfica deste nome.

Figura 3 - Assinatura visual do Curso de Treinamento em Anatomia (CURT@).

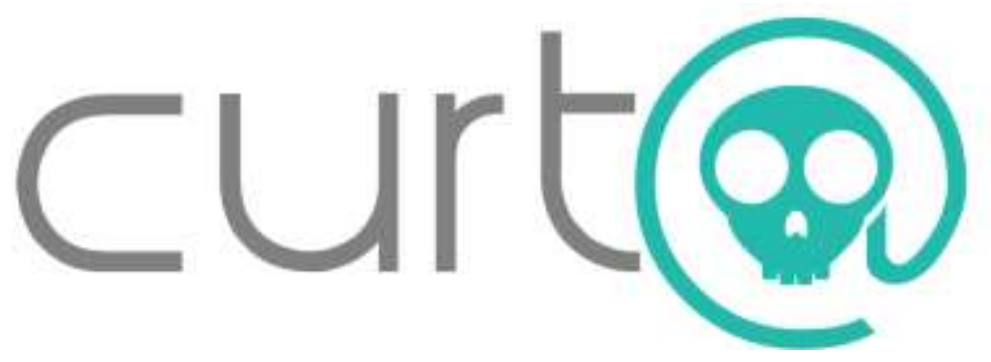

Fonte: Autores.

A assinatura visual do Curt@ foi desenhada por uma equipe formada por duas alunas e uma professora de uma Escola de Belas Artes de uma IFES, com a finalidade de passar as características do ambiente on-line, o seu objetivo e o público que pretende alcançar. A assinatura visual foi idealizada partindo das seguintes ideias: o curtir, no sentido de ter prazer em aprender, de gostar da proposta pedagógica e do ato de curtir as publicações no Moodle e nas redes sociais. 
A caveira estilizada como se fosse um @ , indica que a Anatomia tem um componente on-line. O símbolo da caveira se une ao @ numa simbiose perfeita para demonstrar que a disciplina é semipresencial e visou conectar o aluno ao ensino, ou seja, uma disciplina que até então foi oferecida presencialmente, passou a ser oferecida na modalidade híbrida. Para tal, procurou-se adotar um ensino contextualizado, de forma que a disciplina fosse concebida com base nas necessidades dos futuros professores de Educação Física.

O CURT@ foi estruturado em 10 módulos temáticos, organizados no centro da página, que foi denominada de Timeline (Figura 4). Este ambiente on-line foi planejado para ter algumas características de uma rede social, com o propósito de atrair o aluno. Para esse fim, possui uma Timeline no centro da tela, na qual as postagens foram sendo feitas; com a utilização de imagens, pouco texto e vídeos de curta duração. Na página de abertura do CURT@ foram disponibilizados os links para que o aluno siga os perfis da disciplina nas redes sociais, inserindo-o nos outros dois ambientes on-line.

Figura 4 - Página inicial do Curso de Treinamento em Anatomia (CURT@).

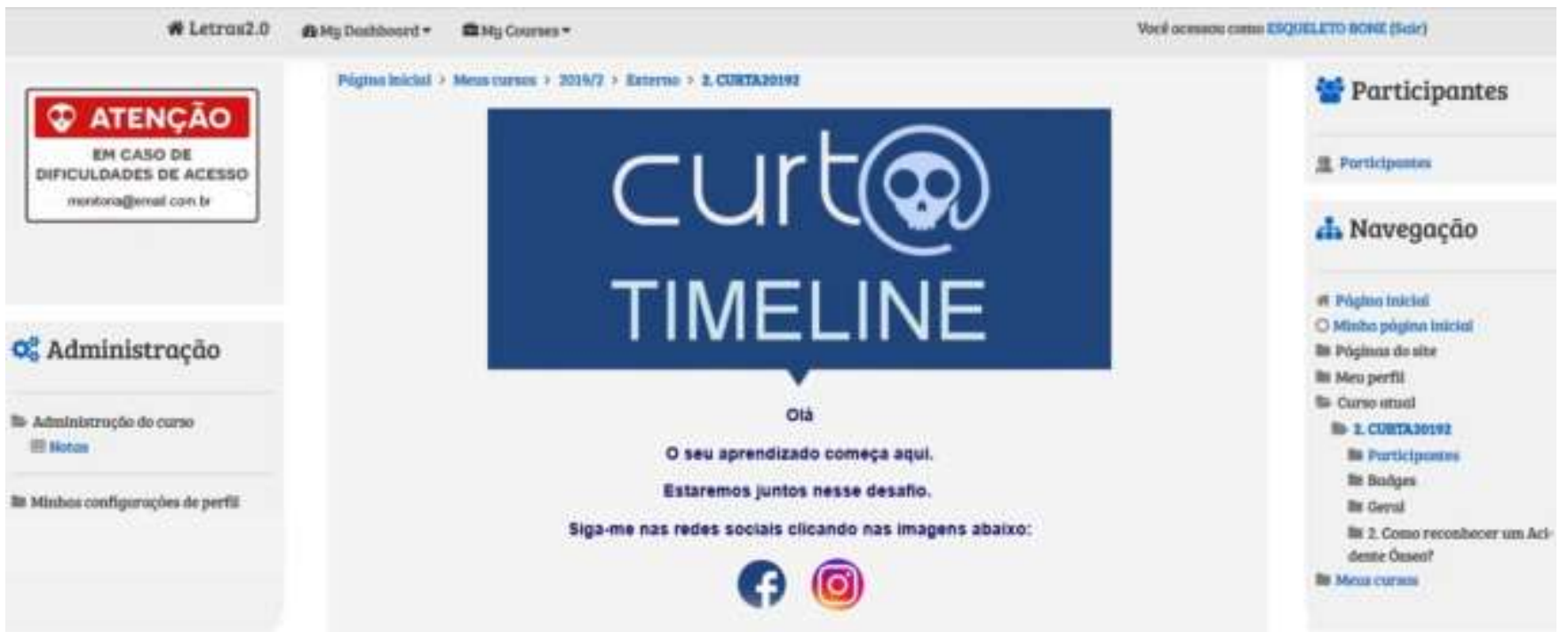

Fonte: Autores.

O CURT@ foi criado na versão 2.6 do Moodle e, pelo fato de ser o ambiente virtual de aprendizagem formal, foi o ponto de partida para estruturação da disciplina. Para dar o suporte pedagógico necessário ao ensino de Anatomia na construção da sala de aula virtual no Moodle, foram utilizadas duas ferramentas: (1) Atividades no Moodle (AM) e (2) Recursos do Moodle (RM). As AM selecionadas foram: questionário, fórum, tarefa e presença, todas valendo nota. Os RM utilizados foram: URL, pasta, arquivo e rótulo (Figura 5). O ambiente virtual formal foi organizado em módulos (tópicos) nos quais todos os conteúdos digitais, AM e RM foram disponibilizados para os alunos. Por meio da plataforma, os alunos tiveram acesso ao cronograma da disciplina, ao material usado na sala de aula presencial e a maior parte das atividades on-line propostas para o aprendizado da matéria (questionário, fórum e tarefa). As outras atividades on-line, complementares ao ambiente formal, foram disponibilizadas nos dois ambientes informais da disciplina (Facebook e Instagram). 
Figura 5 - Infográfico com as atividades e recursos do Moodle utilizados no Curt@.

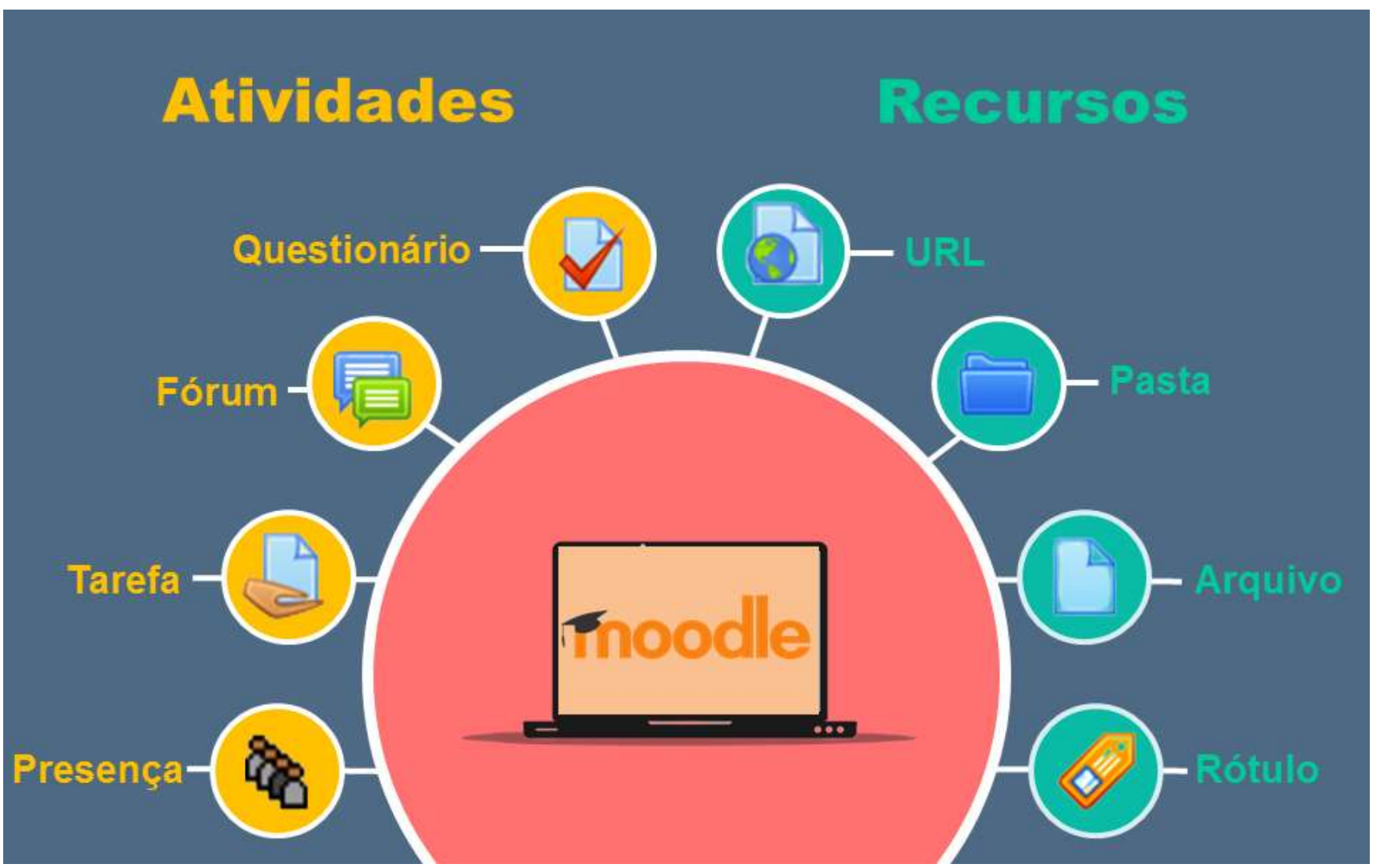

Fonte: Autores.

O questionário constituiu a principal atividade do CURT@. Nomeado de "quiz", foi a única AM que fez parte de todos os módulos do curso. O quiz foi uma atividade on-line, respondido em casa e que preparou o aluno para o momento offline da disciplina. Os quizzes ficavam disponíveis de quinta-feira até o domingo anterior às aulas presenciais. As aulas presenciais aconteciam todas as terças e quintas-feiras, sobre o conteúdo das atividades postadas nos ambientes on-line (Curt@, Facebook e Instagram). As questões foram embaralhadas entre elas, assim como as opções de respostas das múltiplas escolhas. O questionário podia ser respondido várias vezes a cada 4 horas. A chance de refazê-los fez com que o aluno entrasse em uma competição individual, em busca do seu melhor resultado. Quanto ao sistema de notas, sempre foi validada a nota mais alta de todas as tentativas, com o objetivo de evitar a cola e estimular a pesquisa e o aprendizado. Os questionários foram configurados para dar a nota e as respostas erradas a cada tentativa. As respostas corretas não foram disponibilizadas pelo sistema aos alunos. Fazia parte da metodologia adotada, induzir o aluno na busca do conhecimento e ao aprendizado: no seu próprio ritmo, por ensaio e erro, navegando na internet, lendo livros, consultando colegas e tirando as dúvidas presencialmente com a professora. Este tipo de "avaliação semanal" e com consulta, motivou o aluno a manter o estudo em dia.

Depois do questionário, o fórum foi a AM mais utilizada. O tipo de fórum escolhido foi o P e R (perguntas e respostas). Neste fórum, os participantes somente puderam visualizar as respostas dos outros participantes após a postagem de sua própria resposta. As perguntas abertas postadas no fórum foram de pensamento crítico e desafios, no qual os alunos precisavam aplicar algum conhecimento. Não bastava pesquisar sobre o tema, era necessário pensar de forma lógica para encontrar a resposta. $\mathrm{O}$ fórum também ficava disponível de quinta-feira até o domingo anterior às aulas presenciais, com a chance de responder várias vezes e valendo sempre a nota mais alta. À medida que os alunos foram postando suas respostas, a professora foi compartilhando dicas, que ajudaram na resolução do desafio e mantiveram os alunos interessados em solucionar o fórum. 
No Curt@a AM “Tarefa” foi usada para a submissão de trabalhos em equipe. Este tipo de atividade desenvolveu as habilidades para o trabalho em grupo, estimulou a coautoria de conteúdo e aproximou os participantes do grupo. Seguem os tipos de arquivos, com os exemplos entre parênteses, de algumas tarefas desenvolvidas: arquivo de texto (banco de questões elaborado em coautoria pelos alunos); arquivo digital de áudio (podcast sobre determinado tópico da matéria); arquivos de imagens e vídeos (criação de memes e vídeos de anatomia para compartilhamento nas redes sociais da disciplina).

Todas as três AM: questionários, fóruns e tarefas, foram utilizadas na sala de aula invertida, cumprindo o objetivo de tornar o aluno protagonista do seu próprio conhecimento.

A "Presença" foi uma das atividades disponibilizadas na plataforma Moodle, valeu pontos que foram convertidos em nota para o aluno e permitiu manter um registro de presença das aulas off-line diretamente na plataforma. Esta atividade aumentou a assiduidade e a pontualidade do aluno. $\mathrm{O}$ aluno estava presente na aula, do início ao fim, recebeu dois pontos. $\mathrm{O}$ aluno que chegou atrasado ou precisou se retirar antes do final da aula, ganhou um ponto. $\mathrm{O}$ aluno que precisou faltar à aula presencial, não ganhou, mas também não perdeu ponto.

Dos RM (URL, pasta, arquivo e rótulo), a URL foi o mais empregado, usado para disponibilizar links externos ao Moodle e, dessa forma, ampliando o ambiente de aprendizagem. A URL permitiu o compartilhamento de vídeos, memes, textos para consulta (artigos), formulários do Google de autoavaliação do aluno, formulários de avaliação da disciplina etc.

O RM "Pasta" permitiu exibir diferentes arquivos dentro de uma única pasta, evitando a rolagem na página do curso, o que facilitou a visualização para o aluno. Todos os checklists (roteiros para as aulas práticas no laboratório de anatomia), o cronograma da disciplina e a folha padrão de relatório, foram disponibilizados dentro da pasta "Arquivos da Disciplina para Download".

O RM "Rótulo" foi utilizado para inserir as imagens incorporadas na própria página principal (Timeline), sem a necessidade de criar um link para uma página secundária.

Além das AM e RM, a plataforma permitiu que a professora adicionasse um bloco, chamado de "Quickmail", que continha uma lista com os e-mails de todos os participantes do CURT@. Esta ferramenta de e-mail foi utilizada para assuntos pertinentes a algumas atividades e a divulgação da nota das avaliações da disciplina.

\section{Redes Socias - Facebook e Instagram}

A integração do Facebook e Instagram, dois ambientes não formais de aprendizagem com um ambiente formal (Plataforma Moodle), permitiu o compartilhamento de memes, questões de anatomia, avisos importantes, enquetes, vídeos etc. (Figura 6)

O objetivo de ampliar a aprendizagem on-line, em ambientes que não possuem como foco a área educacional, foi aproveitar um espaço de ensino descontraído, menos hierárquico, mais democrático e inclusivo para ensinar anatomia. As redes sociais foram utilizadas para ampliar as interações com os alunos que estavam cursando a disciplina, assim como manter a relação com os ex-alunos, construindo desta forma uma comunidade prática, dando continuidade ao ensino-aprendizagem de anatomia mesmo após o término da disciplina. 
Figura 6 - Meme no Facebook e enquete no Instagram.
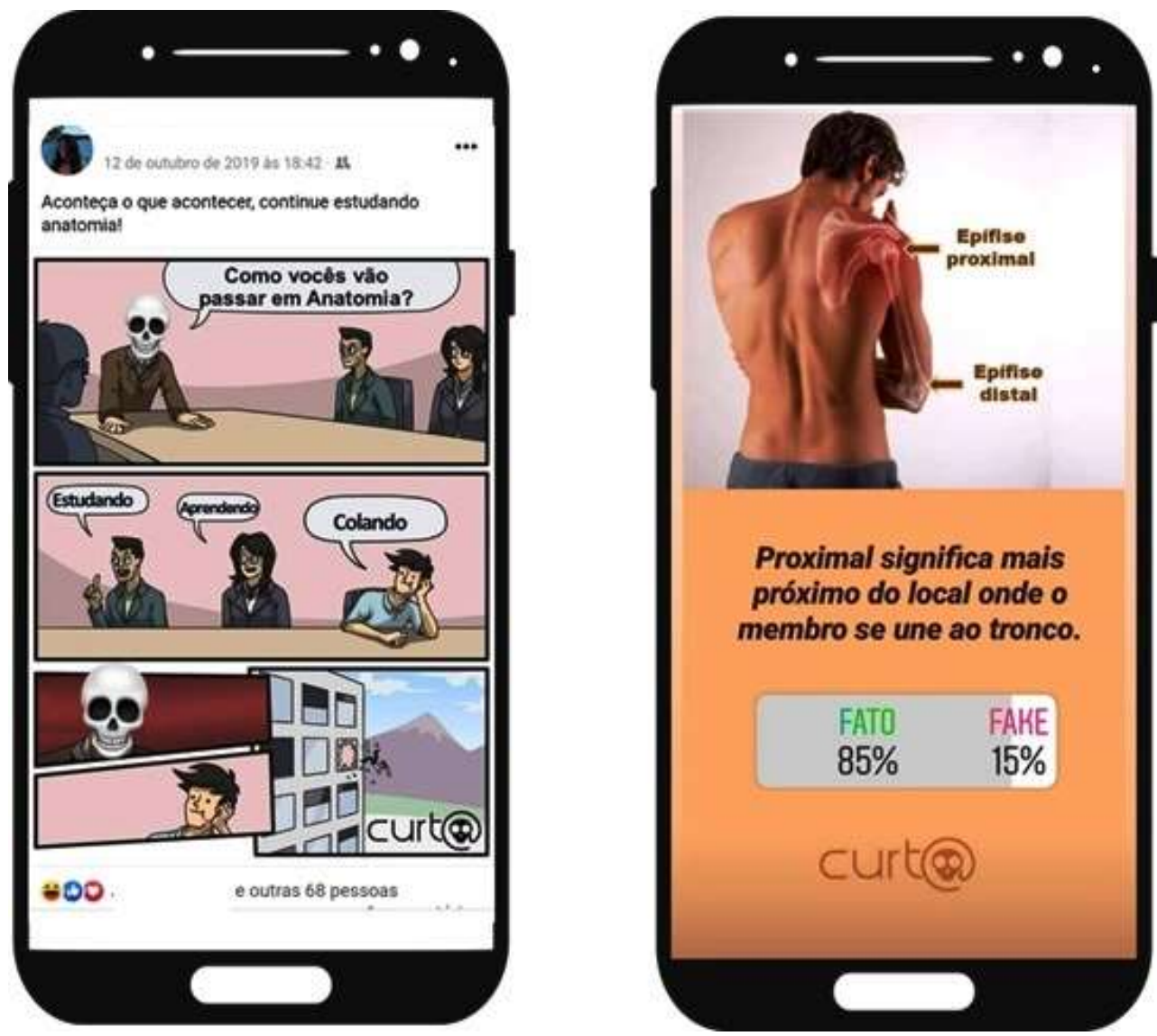

Fonte: Autores.

O fato dos alunos já terem suas contas nas redes sociais e saberem como funciona, ajudou no processo de interação com as atividades propostas neste ambiente, como discutido por Vieira e Bairral (2018). As postagens nas redes sociais, assim que eram publicadas, geravam comentários, curtidas e dúvidas sobre os temas que, na maioria das vezes, foram solucionadas pelos próprios alunos. Este feedback positivo da participação dos alunos, serviu como base para verificar a aceitação da atividade pela turma.

Pactuando com Martins e Baptista (2018), a afetividade dos alunos, na educação on-line, pode ser percebida em comunicação audiovisual, pela forma com que usam os emojis, os memes do Facebook ou ainda pela comunicação textual, observada nos comentários das postagens. As autoras vão além, e comentam que os ambientes on-line proporcionam na turma uma sensação de pertencimento. As redes sociais (Facebook e Instagram) integradas ao ambiente formal de aprendizagem (CURT@) possibilitaram criar laços afetivos com os alunos, e propiciaram uma atmosfera de aprendizagem mais descontraída e informal.

\section{Persona da disciplina - Esqueleto Bone}

Uma das estratégias pensadas para disciplina foi criar uma persona para interagir com os alunos no AMEH. Segundo o blog Max 2 Marketing Digital (2020) o conceito de persona consiste em dar nome e características reais a personagens fictícios. Uma persona representa uma pessoa real e deve possuir as mesmas atitudes e comportamentos de quem ela representa. Posto isso, o personagem fictício criado para disciplina de Anatomia foi o "Esqueleto Bone". Um esqueleto "vivo", presente na lista de chamada da turma, que participou dos ambientes digitais da disciplina e interagiu com a turma pelas redes sociais e pelo Curt@ (Figura 7). 
Figura 7 - Perfil do Esqueleto Bone no Curt@ e no Facebook.
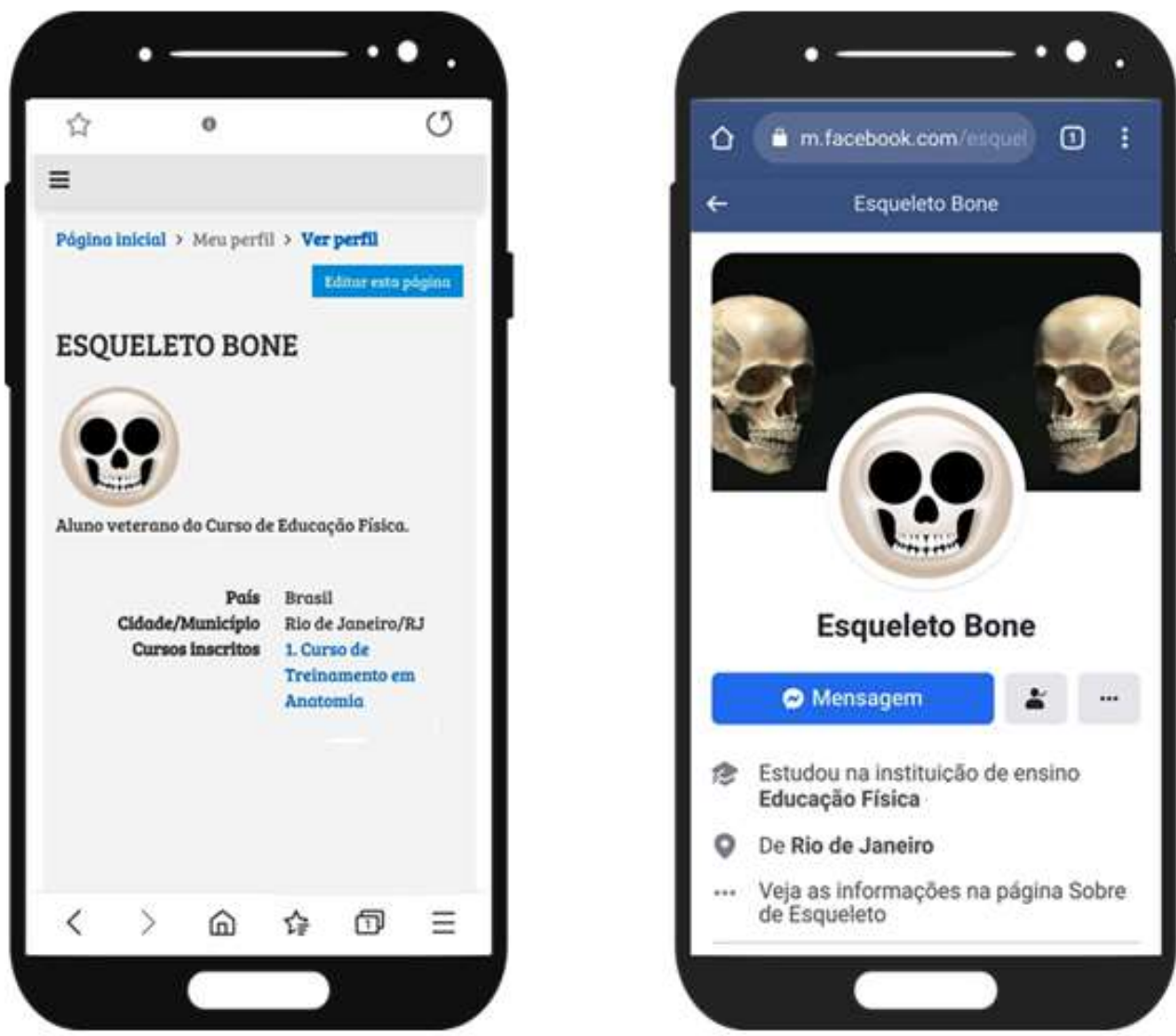

Fonte: Autores.

O personagem foi incorporado ao dia a dia dos alunos, na forma de um aluno veterano, nascido em meados dos anos 90 e que sempre dava boas dicas para os novos alunos nas atividades on-line no curta e nas redes sociais. O objetivo desta incorporação foi deixar a disciplina com características de um RPG (Role-playing game), que é um jogo voltado para criação e interpretação de personagens fictícios. Dessa forma foi criado o aluno "Esqueleto Bone" ou simplesmente "Bone", persona que tinha o objetivo de tornar mais divertida e empática a disciplina de Anatomia.

A escolha de um esqueleto para representar uma pessoa real, surgiu da dificuldade dos alunos de entenderem as funções do esqueleto. O conceito enraizado do esqueleto que se encontra no anatômico, como um material duro, seco, inerte e ligado à morte, dificulta o entendimento que no vivente o esqueleto é uma estrutura viva, dinâmica, adaptável e que está em constante troca metabólica com o organismo (Van de Graaff, 2003). Esta participação, do Esqueleto Bone no papel de aluno da turma, tinha o propósito de desconectar a Anatomia da ideia de morte, tornando a Anatomia mais amigável.

\section{Ambientes off-line de aprendizagem da disciplina}

A anatomia topográfica e voltada para memorização das estruturas anatômicas foi substituída por uma proposta de ensino na perspectiva anatomofuncional, sistêmica, lúdica e com o conteúdo focado nas necessidades dos graduandos da Educação Física. O conteúdo atualizado foi discutido de forma objetiva e dinâmica, com estratégias de aprendizagem que incorporaram níveis de interação a partir dos domínios cognitivos, afetivos e psicomotores. O objetivo geral da disciplina foi aprender sobre a morfologia e função dos sistemas orgânicos aplicados a prática da educação física. Os objetivos específicos de cada conteúdo estão descritos no Quadro 1. 
Quadro 1 - Conteúdos e objetivos específicos.

\begin{tabular}{|c|c|}
\hline Conteúdos & Objetivos específicos \\
\hline Introdução à anatomia & $\begin{array}{l}\text { Explicar a posição anatômica e a sua importância. } \\
\text { Demonstrar os decúbitos do corpo. } \\
\text { Aplicar corretamente os termos anatômicos de posição e direção. } \\
\text { Compreender a relação entre planos, eixos e movimentos. }\end{array}$ \\
\hline Osteologia & $\begin{array}{l}\text { Discutir as funções do esqueleto } \\
\text { Distinguir entre os ossos do esqueleto axial e apendiculares. } \\
\text { Descrever como os ossos crescem em comprimento e diâmetro. } \\
\text { Identificar no seu próprio corpo e no esqueleto, os principais ossos e acidentes ósseos. }\end{array}$ \\
\hline Artrologia & $\begin{array}{l}\text { Distinguir os tipos de articulação. } \\
\text { Explicar a estrutura e função dos componentes de uma articulação. } \\
\text { Executar os movimentos articulares. }\end{array}$ \\
\hline Miologia & $\begin{array}{l}\text { Diferenciar morfofuncionalmente os músculos estriados e lisos. } \\
\text { Explicar a estrutura do músculo esquelético incluindo seus envoltórios de tecido } \\
\text { conjuntivo. } \\
\text { Aplicar os conceitos de contrações isotônicas e isométricas, assim como de agonista e } \\
\text { antagonista. } \\
\text { Reconhecer no cadáver e no próprio corpo os principais músculos. }\end{array}$ \\
\hline Movimentos do tronco e membros & $\begin{array}{l}\text { Descrever ossos, articulações e músculos do tronco e dos membros. } \\
\text { Executar os movimentos do tronco e dos membros, relacionando-os com as ações } \\
\text { musculares, planos e eixos. } \\
\text { Relacionar origem/inserção, direção das fibras do músculo com a ação muscular. }\end{array}$ \\
\hline Sistema nervoso & $\begin{array}{l}\text { Explicar morfofuncionalmente as estruturas do Sistema Nervoso. } \\
\text { Compreender o funcionamento do sistema nervoso somático e visceral. } \\
\text { Explicar o arco reflexo. }\end{array}$ \\
\hline Sistema circulatório & $\begin{array}{l}\text { Descrever as estruturas do sistema circulatório sob o ponto de vista morfofuncional. } \\
\text { Executar a verificação da frequência do pulso radial. }\end{array}$ \\
\hline Sistema respiratório & $\begin{array}{l}\text { Descrever as estruturas do sistema respiratório sob o ponto de vista morfofuncional. } \\
\text { Executar a respiração torácica e a respiração abdominal (ou diafragmática). }\end{array}$ \\
\hline Sistema digestório & Descrever as estruturas do sistema digestório sob o ponto de vista morfofuncional. \\
\hline Sistema geniturinário & Descrever as estruturas do sistema geniturinário sob o ponto de vista morfofuncional. \\
\hline
\end{tabular}

Fonte: Autores.

Assim sendo, as inovações pedagógicas começaram na primeira semana de aula com o uso da modalidade sala de aula invertida. A turma foi convidada por e-mail a participar dos ambientes virtuais da disciplina. As aulas foram on-line com interações propostas no CURT @, Facebook e Instagram. Esta primeira semana de aulas on-line teve como objetivo: acolher os 
alunos, desenvolver interações virtuais entre a professora e a turma; e entre os alunos da turma (quebra-gelo) e ambientar os alunos ao CURT@. Todas as aulas presenciais foram precedidas de atividades nos ambientes virtuais e divididas em dois momentos: (1) uma aula teórica expositiva dialógica com perguntas para sedimentar o conhecimento adquirido no estudo prévio. (2) uma aula prática com resoluções de problemas em equipe e com o uso de diversos recursos. No Quadro 2 o resumo das principais atividades desenvolvidas nas aulas práticas, sobre o sistema locomotor, no laboratório de anatomia.

Quadro 2 - Exemplos de atividades desenvolvidas nas aulas práticas do sistema locomotor.

\begin{tabular}{|c|c|}
\hline Recurso & Descrição da Atividade \\
\hline Esqueleto & $\begin{array}{l}\text { Cada equipe deve montar o esqueleto desarticulado sobre a sua bancada. Após a montagem, a } \\
\text { equipe consulta um esqueleto articulado para comparar e corrigir os erros. A seguir, deve } \\
\text { identificar os ossos no atlas de anatomia visando o aprendizado dos nomes. Após cumprir estas } \\
\text { etapas, os professor e monitores podem intervir e discutir sobre a atividade. }\end{array}$ \\
\hline Peças Cadavéricas & $\begin{array}{l}\text { Executar os movimentos articulares e identificar, sempre que possível no próprio corpo e nas } \\
\text { peças cadavéricas, os músculos que estão em ação. }\end{array}$ \\
\hline Cubo Mágico & $\begin{array}{l}\text { Etiquetar o cubo mágico com os seis planos tangenciais do corpo (cranial, caudal, anterior, } \\
\text { posterior, lateral direito e lateral esquerdo). Identificar os nomes e a direção dos eixos que } \\
\text { atravessam os planos tangenciais no cubo mágico. Identificar os planos de secção do corpo e os } \\
\text { movimentos. Demostrar com o auxílio do cubo mágico os movimentos articulares, os planos de } \\
\text { secção e os eixos (Figura 8). }\end{array}$ \\
\hline Desafio Anatômico & $\begin{array}{l}\text { Escolher um mau hábito postural, observado em sala de aula, em estudantes do ensino médio; e } \\
\text { sugerir um exercício ou uma atividade para compensar o desvio postural adquirido com o mau } \\
\text { hábito. }\end{array}$ \\
\hline Aparelho de Musculação & $\begin{array}{l}\text { A equipe deve escolher um aparelho de musculação. Depois, cada participante da equipe deve } \\
\text { executar o movimento permitido no aparelho para perceber, no próprio corpo, a articulação } \\
\text { responsável pelo movimento e os músculos que estão sendo trabalhados. Logo após esta etapa, } \\
\text { discute-se sobre a ação articular, o plano, o eixo, os tipos de contração (distinguir entre os } \\
\text { momentos concêntrico/excêntrico) e identificar os músculos agonistas/antagonistas. Após a } \\
\text { finalização da atividade, cada equipe faz uma breve apresentação para turma, executando o } \\
\text { movimento no aparelho de musculação e explicando o que foi aprendido (Figura 8). }\end{array}$ \\
\hline Jogo de Cartas & $\begin{array}{l}\text { Iniciar a atividade distribuindo um baralho, sem as regras do jogo, por equipe. É importante } \\
\text { destinar um tempo para a equipe manusear livremente as cartas, dando a oportunidade de } \\
\text { conhecer o baralho. Em seguida, a equipe deve criar um critério para classificar as cartas, } \\
\text { dividindo as cartas em categorias. Uma vez decidido qual o critério vai utilizar para classificar } \\
\text { as cartas, a equipe deve tentar explicar a lógica do jogo. Com o auxílio do baralho, as equipes } \\
\text { devem responder a duas pergunta: (1) Quais são as articulações que compõem o jogo canastra } \\
\text { anatômica? e (2) O que pode ser aprendido com o jogo "Canastra Anatômica"? Logo depois são } \\
\text { distribuídas as regras e os alunos são convidados a jogar a "Canastra Anatômica". }\end{array}$ \\
\hline
\end{tabular}


Figura 8 - Recursos: Cubo mágico / Aparelho de musculação.

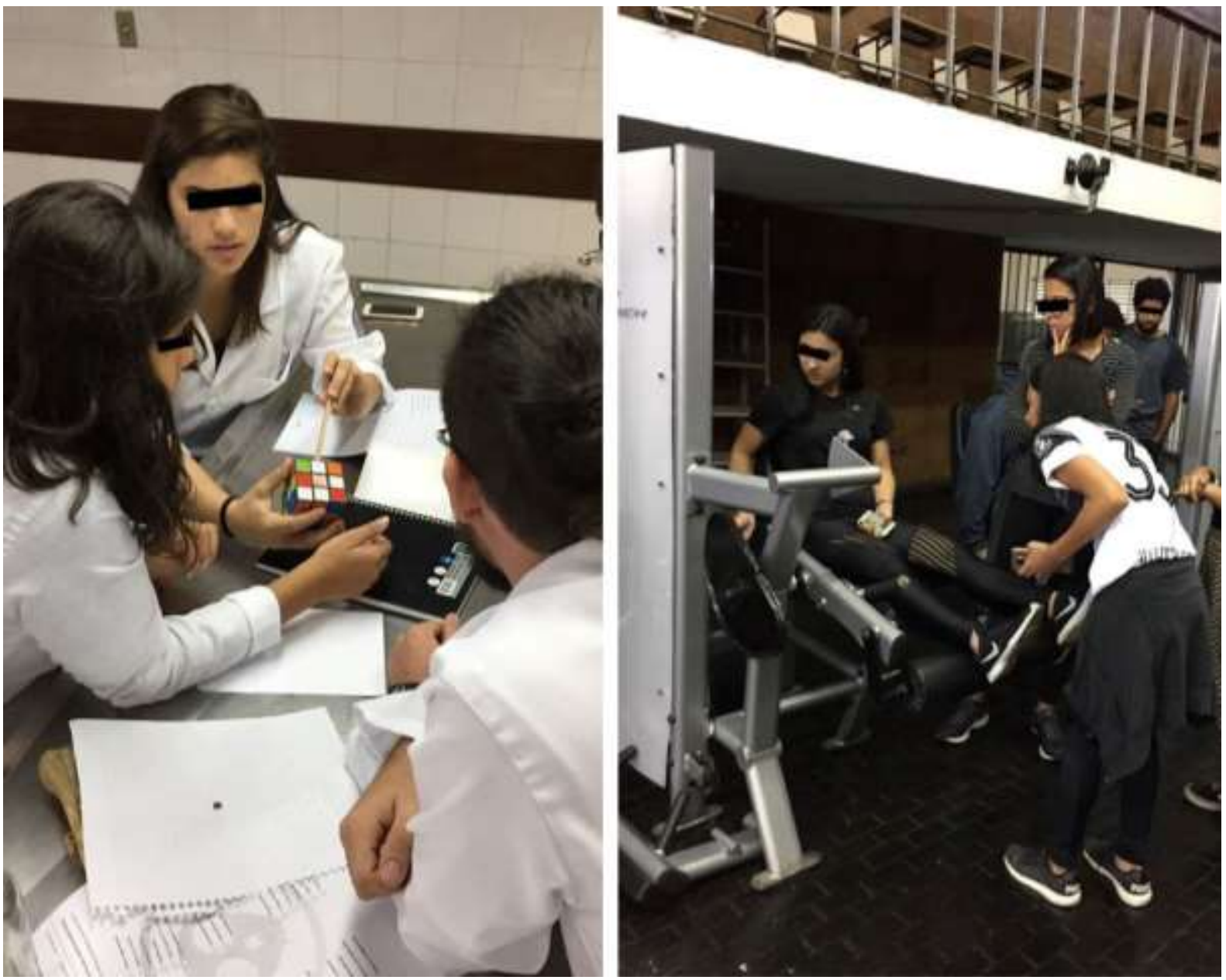

Fonte: Autores.

As metodologias ativas de aprendizagem aplicadas nas aulas práticas de anatomia, com a utilização de diferentes recursos e um estudo contextualizado das estruturas anatômicas, foram planejadas para desenvolver competências e habilidades na área da educação física. A aula prática estimulou o aprendiz a articular as informações adquiridas com o estudo prévio no Curt@, com as que foram apresentadas na aula presencial. A dinâmica da aula mudou e o aluno teve a oportunidade de discutir os conteúdos estudados em equipe, nas aulas práticas no anatômico, e sanar as dúvidas da matéria. Concordando com Moran (2015, p. 17), que afirma que para aprender, tem que experimentar e que "a melhor forma de aprender é combinando equilibradamente atividades, desafios e informação contextualizada". O modelo pedagógico proposto estimulou a participação ativa da turma na construção de um conhecimento sólido, tornando o aluno capaz de aplicar os conteúdos aprendidos na disciplina de Anatomia em outros contextos.

\section{Sistema de avaliação gamificado}

O sistema de avaliação da disciplina de Anatomia foi todo construído em cima de uma estrutura gamificada. Concordando com Fardo (2013), os elementos dos jogos são ferramentas valiosas para criar experiências educacionais significativas nos ambientes de aprendizagem, impactando de forma positiva, motivando e aumentando a participação do aluno em todo o processo.

No processo de gamificação planejado para disciplina, os alunos receberam pontos por todas as atividades 
desenvolvidas no AMEH. A avaliação foi além da prova escrita, considerou-se uma variedade de instrumentos avaliativos: presença nas aulas teóricas e práticas; relatórios das aulas práticas; trabalhos em grupo; quizzes; fóruns de pergunta e respostas; enquetes nas redes sociais e qualquer outra tarefa, executada pelo aluno, passou a compor o quadro de notas e foi considerada como instrumento de avaliação.

O propósito de desafiar constantemente os alunos, utilizando elementos dos jogos, foi manter o interesse no aprendizado da matéria. Na maioria dos jogos, o sistema de pontuação ajuda a classificar os jogadores a partir de um ranqueamento. $\mathrm{Na}$ estrutura de gamificação da disciplina, os alunos precisaram demonstrar aprendizado nas atividades propostas nos ambientes on-line e em sala de aula presencial, para ganhar pontos e concorrer a um dos certificados.

Três certificados foram utilizados no sistema de recompensa da disciplina: o certificado "Vip Bronze", o certificado "Vip Prata" e o certificado "Vip Ouro". Os certificados valem horas em "atividades complementares", que são componentes dos currículos de formação universitária. Essas atividades visaram uma ampliação do saber e o exercício da autonomia acadêmica do educando. A carga horária, pela participação no Curso de Treinamento em Anatomia - CURT@, foi contabilizada como créditos para os alunos, por ser uma atividade extra, de ampliação do conhecimento, que foi desenvolvida fora do horário de aula da disciplina. (Figura 9).

Figura 9 - Modelo do Certificado Vip Ouro - aluno fictício Esqueleto Bone.

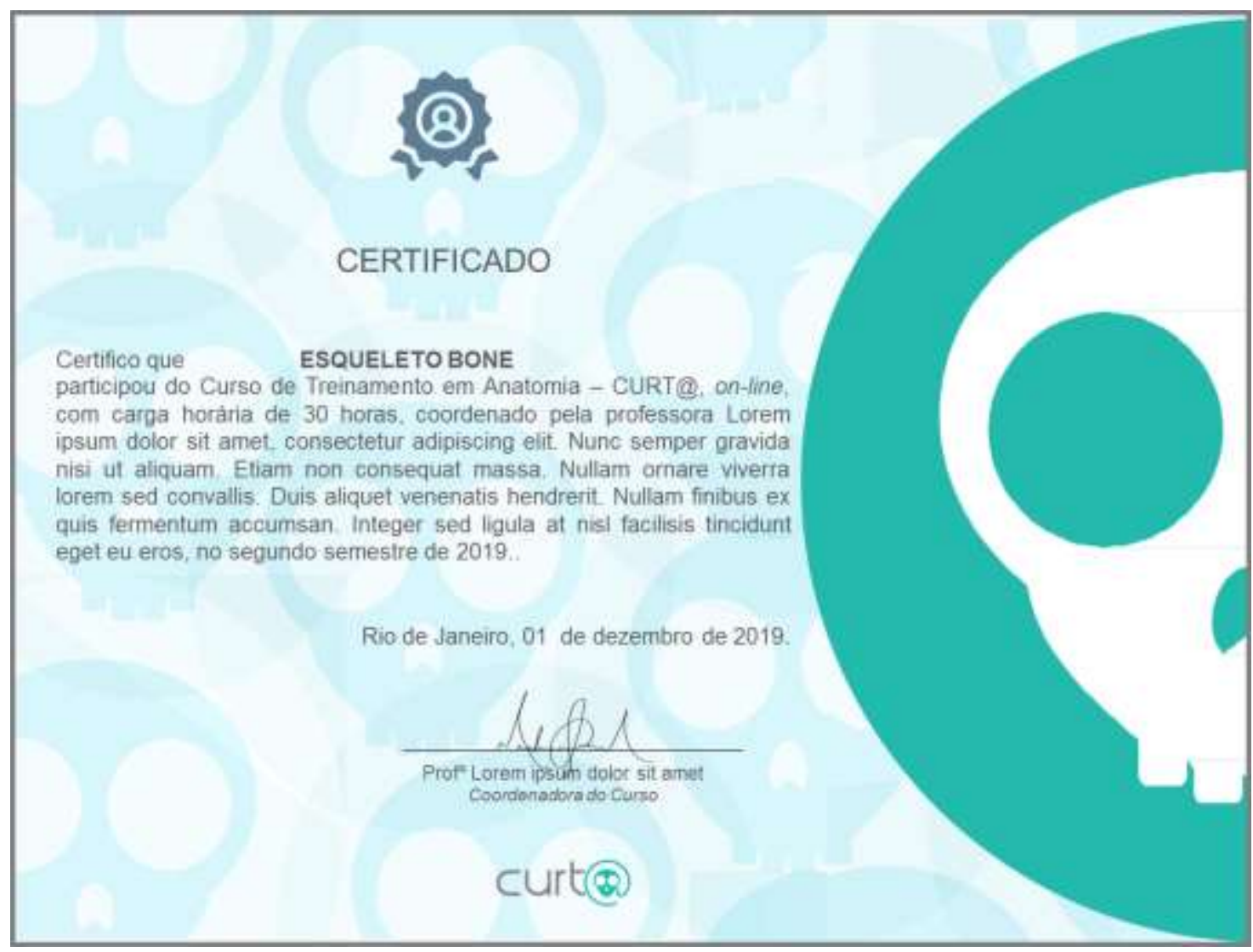

Fonte: Autores.

Foi criado também um conjunto de critérios para ganhar o certificado. O aluno foi somando pontos à medida que executa as atividades tanto on-line, como nas propostas em sala de aula presencial, como se fossem níveis alcançados pelo jogador. E não bastava ganhar os pontos, tinha que validar os pontos. Para validar os pontos foi preciso ter no mínimo a média aritmética das quatro avaliações escritas maior ou igual a seis, 90\% de presença nas aulas e a nota do AVA tinha que ser maior 
ou igual a sete. Com esse desempenho o aluno ganhava o certificado Vip Bronze, que simbolizava o nível do seu aprendizado na disciplina e correspondia a 10 horas complementares, relativas ao tempo que ele passou no ambiente virtual de aprendizagem fora do horário de aula. Para ganhar o certificado Vip Prata, que corresponde a 20 horas complementares, o aluno teve que tirar nota maior ou igual a seis em cada uma das quatro avaliações escritas, ter $90 \%$ de presença nas aulas e a nota do AVA tinha que ser também maior ou igual a sete. $O$ aluno que conseguiu tirar nota maior ou igual a sete em cada uma das quatro avaliações escritas, ter $90 \%$ de presença nas aulas e uma nota no AVA maior ou igual a sete, recebeu o certificado Vip Ouro, que correspondia a 30 horas complementares. A estrutura gamificada da disciplina manteve o aluno ativo, empenhado em cumprir as tarefas e aprender a matéria, pois ele almejava ganhar o certificado Vip Ouro

\section{Considerações Finais}

A proposta de estruturação da disciplina de Anatomia para Educação Física está de acordo com o projeto pedagógico do curso. Foi planejada uma disciplina voltada para formação de habilidades e competências como a compreensão morfofuncional dos sistemas orgânicos, com ênfase no sistema locomotor e sua aplicação nos diversos contextos do futuro professor.

As experiências desenvolvidas e analisadas, durante oito semestres, demonstraram que a alteração de um contexto de ensino presencial para um ensino semipresencial, é inevitável ao se construir um modelo de disciplina para o século XXI.

$\mathrm{Na}$ hibridização da disciplina de Anatomia foi escolhida a modalidade "sala de aula invertida" que é uma contraposição à sala de aula tradicional, sendo baseada na discussão sobre os papéis de alunos e professores. Ao se adotar a modalidade híbrida da sala de aula invertida, se rejeita o modelo tradicional em que o professor apresenta os conteúdos para os alunos absorverem e reproduzirem.

Cada aluno aprende de forma diferente. Portanto, é de extrema importância que o professor, ao criar um Ambiente de Ensino Híbrido, utilize as diferentes modalidades de ensino como estratégia para atender aos vários tipos de aprendizes (auditivos, visuais, verbais e cinestésicos).

Quanto à avaliação, deve ser um processo sistemático, progressivo, contínuo e com feedbacks imediatos. É preciso avaliar a aprendizagem de múltiplas formas e incentivar o protagonismo do aluno na busca constante pelo conhecimento. $\mathrm{O}$ processo avaliativo da disciplina foi muito além de provas escritas; todas as tarefas executadas pelos alunos compuseram um sistema de notas gamificado e foram consideradas instrumentos de avaliação.

Sobre as redes sociais, elas podem ser uma ferramenta para ampliar as interações com os alunos, assim como manter a relação com os ex-alunos, construindo desta forma uma comunidade, dando continuidade ao ensino-aprendizagem da disciplina, mesmo após o término da mesma.

Vale destacar que esse estudo não está fechado e nem acabado. O artigo não teve como objetivo apontar uma solução pronta para o ensino de Anatomia. Tão somente teve como objetivo trazer uma alternativa ao ensino tradicional, de fácil aplicação, sugerindo mudanças progressivas em direção à hibridização do ensino.

Espera-se que a proposta apresentada possa contribuir para o ensino-aprendizagem de Anatomia para os graduandos da Escola de Educação Física. E embora essa proposta tenha sido estruturada para disciplina de Anatomia, supõe-se que possa ser adotada em outras disciplinas, com as devidas adaptações.

\section{Referências}

Alexander, B., Ashford-Rowe, K., Barajas-Murphy, N., Dobbin, G., Knott, J., McCormack, M., Pomerantz, J., Seilhamer, R., \& Weber, N. (2019). Horizon Report 2019 Higher Education Edition. EDU19. https://www.learntechlib.org/p/208644/.

Bacich, L. (2020). Ensino híbrido: esclarecendo o conceito. Inovação na Educação. https://lilianbacich.com/2020/09/13/ensino-hibrido-esclarecendo-oconceito/ 
Bacich, L., \& Moran, J. (2015). Aprender e ensinar com foco na educação híbrida. Revista Pátio, 25, 45-47.

Bacich, L., \& Moran, J. (2018). Metodologias ativas para uma educação inovadora. Penso.

Bergmann, J., \& Sams, A. (2012). Flip Your Classroom: Reach Every Student in Every Class Every Day. Iste.

Bernardo, K. F., Silva, T. C. S., Amorim, L. P., Borges, A. E. de A., \& Barros, V. K. A. (2020). O uso do Facebook enquanto espaço pedagógico. Brazilian Journal of Development, 6(1), 838-846.

Boucherville, G. C. de. (2019). Didática do Continuum: a sala de aula na cultura digital. Tese (Doutorado em Educação) - Programa de Pós-Graduação em Educação da Pontifícia Universidade Católica de Minas Gerais, Belo Horizonte.

Crochemore, M., \& Marques, A. (2017). Disciplina de Anatomia Humana no curso de Licenciatura em Educação Física: considerações de egressos sobre sua relevância para prática docente. Revista Thema, 14(1), 8-28.

Deming, W. E. (1990). Qualidade: a revolução da administração. Marques-Saraiva.

Deterding, S., Dixon, D., Khaled, R., \& Nacke, L. (2011). Game Design Elements to Gamefulness: Defining "Gamification”. Proceedings of the 15th International Academic MindTrek Conference: Envisioning Future Media Environments, 9-15.

EEFD. (2006). Projeto Pedagógico Licenciatura em Educação Física. https://www.eefd.ufrj.br/sinaes/projeto-pedagógico-do-curso-de-graduação-emeducação-física

Fardo, M. L. (2013). A gamificação aplicada em ambientes de aprendizagem. Renote, 11(1), 1-9.

Fonseca, E. M. da, \& Duso, L. (2018). Reflexões no Ensino de Ciências : Elaboração e análise de materiais didáticos. Revista de Produtos Educacionais e Pesquisas em Ensino, 2(1), 23-44.

Fontes, F. L. de L., Bezerra, A. M. F. de A., Silva, H. L. L. da, Santo, I. M. B. do E., Marques, T. M. C., Morais, M. J. A., Ribeiro, R. do N., Barros, D. de M., Dantas, M. S. M., Sousa, M. S. R. de, Silva, N. K. B. da, Barbosa, S. V. N., \& Melo, M. M. (2021). Utilização de metodologias ativas no curso de graduação em Enfermagem: uma oportunidade de superação do modelo de ensino tradicional. Research, Society and Development, 10(1), e35410111774.

Freire, P. (1987). Pedagogia do Oprimido (17ºd). Paz e Terra.

Gasque, K. C. G. D. (2016). Internet, mídias sociais e as unidades de informação. Brazilian Journal of Information Science, 10(2), 14-20.

Kapp, K. (2013). Thinking about gamification in learning and instruction. http://karlkapp.com/thinking-about-gamification-in-learning-and-instruction/

Lacerda, A. L. de, \& Silva, T. da. (2016). Avaliação de uso de AVA no Ensino de Física. ALEXANDRIA Revista de Educação em Ciência e Tecnologia, 9(1), 293-314.

Massari, C. H. de A. L., Flôres, L. S., Santos, J. M. L., Turquetti, A. de O. M., Miglino, M. A., \& Júnior, J. R. K. (2020). O ensino de imunologia na graduação de medicina veterinária. Revista de Graduação USP, 4(1), 111-118.

MAX2. (2020). Aprenda como criar a persona ideal para sua estratégia digital! http://blog.max2digital.com.br/analytics-e-performance/aprenda-como-criara-persona-ideal-para-sua-estrategia-digital/

Montes, M. A. de A., \& Souza, C. T. V. de. (2010). Estratégia de ensino-aprendizagem de anatomia humana para acadêmicos de medicina. Ciências \& Cognição, 15(3), 2-12.

MoodleNet. (2021). Statistics. https://stats.Moodle.org/

Moore, K. L., Dalley, A. F., \& Agur, A. M. R. (2014). Anatomia orientada para a clínica (7ºd). Guanabara Koogan.

Moran, J. (2015). Mudando a educação com metodologias ativas In: Souza, C. A.; Morales, O. E. T. (org.). Coleção Mídias Contemporâneas. Convergências Midiáticas, Educação e Cidadania: aproximações jovens.: Vol. II. (p. 15-33). UEPG/PROEX.

Moran, J., Masetto, M. T., \& Behrens, M. A. (2013). Novas Tecnologias e Mediação Pedagógica (21ํed). Papirus.

Pereira, P. F. de O., Fiuza, P. J., \& Lemos, R. R. (2019). Aprendizado baseado em jogos digitais no ensino de anatomia utilizando gamificação: uma revisão sistemática da literatura. Criar Educação, 8(1), 1-13.

Pereira, W. O., \& Lima, F. T. (2018). Desafio, Discussão e Respostas: estratégia ativa de ensino para transformar aulas expositivas em colaborativas. Einstein (Sao Paulo, Brazil), 16(2), 1-4.

Piazza, B. L., \& Chassot, A. I. (2011). Anatomia Humana, uma disciplina que causa evasão e exclusão: quando a hipótese principal não se confirma. Ciência em Movimento, 14(28), 45-59.

Ramos, L. V., Teixeira, L. H. S., \& Belém, M. O. P. (2020). Uso de metodologias ativas no ensino da Anatomia Humana: um relato de experiência na educação profissional da Bahia. Revista Estudos IAT, 5(3), 327-339.

Roschel, H., Tricoli, V., \& Ugrinowitsch, C. (2011). Treinamento físico: considerações práticas e científicas. Revista Brasileira de Educação Física e Esporte, 25(spe), 53-65

Schultz, M. (2017). Contemporaneidades do Ensino de Anatomia Humana. Revista de Graduação USP, 2(1), $151-154$. 
Research, Society and Development, v. 10, n. 9, e40410918247, 2021

(CC BY 4.0) | ISSN 2525-3409 | DOI: http://dx.doi.org/10.33448/rsd-v10i9.18247

Silva, A. J. de C. (2020). Guia prático de Metodologias Ativas com uso de Tecnologias Digitais da Informação e Comunicação. UFLA.

Tripp, D. (2005). Pesquisa-ação: uma introdução metodológica. Educação e Pesquisa, 31(3), 443-466.

Van de Graaff, K. M. (2003). Anatomia Humana (6 ${ }^{\circ}$ ed). Manole.

Vieira, B., \& Bairral, M. A. (2018). Aprender no Facebook: alguns silêncios e ruídos para investigar o ensino e a docência online. Revista Docência e Cibercultura, 2(2), 68-83

WE ARE SOCIAL. (2020). Digital in 2020. https://wearesocial.com/uk/digital-2020

Williams, P. L., Warwick, R., Dyson, M., \& Bannister, L. H. (1995). Gray Anatomia (37º ed). Guanabara Koogan.

Yamaguchi, M. U., Barros, J. K. de, Souza, R. C. de B., Bernuci, M. P., \& Oliveira, L. P. de. (2020). O papel das mídias digitais e da literacia digital na educação não-formal em saúde. Revista Eletrônica de Educação, 14, 1-11. 